\title{
CONTAÇÃO DE HISTÓRIAS: FORMAÇÃO, ATUAÇÃO E ENSINO
}

\author{
Valéria da Silva Lima*, Maylta Brandão dos Anjos e Giselle Roças \\ E-mail: valeriaslima8910@yahoo.com.br \\ Instituto Federal de Educação, Ciência e Tecnologia do Rio de Janeiro
}

DOI: $10.15628 /$ rbept.2020.11325

Artigo submetido em: out/2020 e aceito em: dez/2020

\begin{abstract}
RESUMO
A Contação de Histórias é um campo profissional que permeia a Pós-Graduação, no sentido da formação para atuação educativa. Nesse sentido este estudo integra a Tese de Doutorado desenvolvida no PROPEC-Programa de Pós Graduação strictu sensu em Ensino de Ciências do IFRJ. Pretende-se investir na formação do professor que atua nos anos iniciais para que ao ensinar Ciências utilize a arte de Contar Histórias para seus alunos relacionando às questões da ciência, sociedade e tecnologia. A pesquisa está baseada no paradigma da crítica social amparada em Freire (2019) em que o contexto social é premissa para a transformação coletiva no viés da pesquisa participante de Brandão e Streck (2017). Apresentaremos algumas técnicas de contação de histórias realizadas no percurso da pesquisa e breves análises de 3 canais do Youtube em que profissionais, com formações distintas, contam histórias envolvendo temas diversos. Que a arte de contar histórias seja elemento de diálogo entre a Pós-Graduaçao e a sala de aula no sentido da formação para a transformação social.
\end{abstract}

Palavras-chave: Educação. Ensino. Pós-Graduação. Histórias infantis.

\section{STORYTELLING: TRAINING, ACTING AND TEACHING}

\begin{abstract}
Storytelling is a professional field that permeates the Graduate Program, in the sense of training for educational activities. In this sense, this study is part of the Doctoral Thesis developed in the PROPEC-Strictu sensu Graduate Program in Science Teaching of IFRJ. It is intended to invest in the training of the teacher who works in the early years so that when teaching Science uses the art of Storytelling for its students relating to the issues of science, society and technology. The research is based on the paradigm of social criticism based on Freire (2019) in which the social context is a premise for collective transformation in the bias of the participant research of Brandão and Streck (2017). We will present some storytelling techniques, carried out in the course of the research and brief analyses of 3 Youtube channels in which professionals, with different backgrounds, tell stories involving various topics. May the art of storytelling be an element of dialogue between the Graduate Program and the classroom in the sense of formation for social transformation.
\end{abstract}

Keywords: Education. Teaching. Graduate. Children's stories. 


\section{INTRODUÇÃO}

Apresentamos a Contação de Histórias como um elemento de formação docente que pode acontecer no nível da Pós Graduação para atuação nas docências. Com as mudanças nas demandas sociais, a profissionalização do contador de histórias faz-se necessário para o desempenho no exercício da função.

Em dias atuais, com o avanço das novas tecnologias da informação e comunicação, novas formas de contar histórias foram surgindo. Para dar conta das demandas sociais, investir na pesquisa faz-se necessário. A formação do profissional para atuar no campo da Contação de histórias é de relevância. $\mathrm{Na}$ medida em que auxiliará sujeitos de forma coletiva e participativa no movimento de transformação de pessoas no exercício da profissão.

A escolha da temática se deu pela nossa atuação como docente dos anos iniciais que nos levou a investirmos em nossa formação continuada para melhoria da prática cotidiana. Inicialmente, participamos de cursos de curta duração na Rede Municipal em que exercemos a docência, depois na graduação e em seguida em curso de especialização. No mestrado e doutorado continuamos inseridos na pesquisa voltada para a ação social. Essa pesquisa valoriza a Contação de História como exercício profissional que pode ser utilizada como elemento para o ensino em uma concepção interdisciplinar.

Dessa forma, pesquisar sobre a Contação de História e o trabalho de profissionalização docente foi uma das formas que descobrimos para tornar a pesquisa participativa em que academia e sociedade podem dialogar na formação do leitor crítico e reflexivo.

Compreendemos que uma das finalidades do Ensino Superior é atuar para universalizar e aprimorar a educação básica, por meio da formação e capacitação de profissionais articulando teoria e prática. Pesquisas pedagógicas, ensino e extensão podem aproximar os níveis escolares. (BRASIL, 2019).

A aproximação entre os níveis escolares se deu por meio de oficinas, mini-cursos e ministração de oficinas para professores da Educação Básica, licenciandos e alunos do curso de Formação Continuada e Inicial do Instituto Federal de Educação, Ciência e Tecnologia do Rio de Janeiro, campus avançado de Mesquita. As ministrações de disciplinas no curso FIC de Contação de Histórias aconteceram após o término do Mestrado em que a mediamos a formação de contadores de histórias, investimos na formação profissional para atuação em espaços distintos escolares e não escolares.

Em dias atuais, espaços e tempos são mensurados de formas distintas, o contador de histórias saiu do espaço comunitário local para atuar no espaço 
global cibernético (BUSATTO, 2007). Diante disso, métodos, técnicas, dinâmicas e novos desafios surgem para a atuação desse profissional.

Investir na profissionalização do Contador de Histórias é formar sujeitos para atuação em espaços dinâmicos que podem dialogar com o Ensino de Ciências incluindo a sociedade e as tecnologias. Eles podem estar presentes nos níveis do ensino que vão desde a Educação Infantil ao Ensino Superior, nas modalidades que incluem a Educação de Jovens e Adultos, a Educação Tecnológica e a Educação Especial envolvendo a teoria e prática.

Para que as histórias fluam e auxiliem o docente nos aspectos do trabalho com a formação do leitor, no ensino de ciências, na arte criativa para a compreensão do mundo, é preciso formar o profissional capaz de lidar com as demandas diversas.

Diante disso, o objetivo geral busca colaborar para a formação do professor contador de Histórias. Fornecer orientações e dicas para o exercício do trabalho profissional e inserção social. Preservar o diálogo entre PósGraduação e espaço de trabalho educativo por meio de práticas de Contação de Histórias.

Os objetivos específicos buscam: sugerir dicas e técnicas de histórias a serem dinamizadas no trabalho com a Contação de Histórias. Apresentar maneiras para ampliar o repertório das contações de histórias na atualidade.

Para Busatto (2007) um sujeito que estava com pouco movimento, voltou a ocupar seu lugar social. A palavra do contador de histórias tem ocupado diversos espaços na atualidade. Diante disso, as relações com a profissionalização e o trabalho surgem como campo de estudos para a transformação social que é práxis, ação e reflexão ( FREIRE, 2020).

A contação de histórias é um elemento de arte, ensino, enunciação, resgate de memória, incentivo à imaginação, ressignificação e transformação social para a ciência, a tecnologia e a sociedade. Por isso, trata-se de um processo educativo que humaniza, sendo capaz de compartilhar saberes e dá sentido à vida.

A formação do professor no nível da pós-graduação deve educar não somente para a academia, mas para a inserção social, do mundo, da vida e do contexto. Uma educação que trabalhe com os problemas reais. Dessa forma, a Universidade precisa se abrir para novos tempos, novos caminhos. (CENDALES, TORRES, 2017).

No artigo 42 da Lei de Diretrizes e Bases da Educação Nacional 9394/96, o inciso III afirma que é preciso:

Incentivar o trabalho de pesquisa e investigação científica, visando o desenvolvimento da ciência e da tecnologia e da criação e difusão da cultura, e, desse modo, desenvolver o 
entendimento do homem e do meio em que vive. (BRASIL, 2019, [n.p]).

Compreendemos que o Ensino de Ciências está em amplo processo de crescimento, em especial em tempos de pandemia por conta da Covid-19. Nesse sentido, pesquisas na pós-graduação e investimentos científicos na realidade social são caminhos fundamentais para a construção de conhecimentos.

O que as histórias contam e suas colaborações para as docências no Ensino de Ciências dos anos iniciais faz parte de nosso estudo. As histórias abrem portas para a imaginação, tratam dos saberes desde o senso comum aos científicos e ensinam sobre a vida. Podem ser dinamizadas como terapia, consolo, entretenimento, cura e ensino, logo é preciso sair do senso comum e caminhar para a construção do conhecimento.

Nas linhas seguintes apresentaremos alguns caminhos para a formação do Contador de Histórias, tendo em vista a inserção na profissionalização do trabalho para a mudança e transformação social.

\section{TRABALHO COM A CONTAÇÃO DE HISTÓRIAS ANTES E AGORA}

Em épocas passadas, a Contação de Histórias era representada por um sujeito que poderia ser um ancião, griô, guardião de memórias, um pajé que tinha em seu bojo toda cultura de uma comunidade local. O conhecimento africano dos griôs, na Africa primitiva, dos povos indígenas, dos contadores de histórias, de Sherazade era um saber apresentado pela palavra oral a um grupo ou pessoas específicas de certa comunidade.

Contar histórias é um dos hábitos mais antigos da humanidade. Criada como profissão, nas últimas décadas do século XX, a arte de contar histórias sempre esteve presente na alma da comunidade. O contador de histórias é de fundamental importância para a preservação e transformação sociocultural de um povo. (CARVALHO, 2015, p. 5)

Para Bâ (2010) o conhecimento é global e vivo. Os anciãos, que foram os últimos depositários orais são comparados a vastas bibliotecas como múltiplas prateleiras ligadas por meio de relações invisíveis e formam a "ciência do invisível", chanceladas por correntes de comunicação iniciática.

Atualmente, a contação de Histórias abrange processos mais amplos e a comunidade local cedeu espaço para a comunidade global. Dessa forma, as 
maneiras de enunciação mudaram. Novas formas, adereços, técnicas e diálogos com campos diversos são necessários.

Ensinar não é transferência de conhecimento, mas um testemunho vivo. O professor deve levar em conta sua competência profissional, deve estudar, se esforçar para que sua ação tenha qualidade. (FREIRE, 2019). A pesquisa faz parte da ação docente, não há ensino sem pesquisa, nem pesquisa sem ensino. (FREIRE, 2019).

Ao abordarmos a arte de Contar Histórias tratamos de linguagens distintas expressas no teatro, na música, na dança e nas artes visuais. Contar Histórias difere das linguagens acima apresentadas no sentido específico de produção. Porém, nesses campos de conhecimentos existem manifestações em que a contação de histórias se faz presente e deve ser valorizada para a profissionalização e ensino.

Diante dos fatos citados anteriormente, estudar sobre a Contação de Histórias como campo de conhecimento exige aprofundamentos para que o profissional adquira formação em que a teoria e a prática estejam aliadas. $O$ movimento emancipatório perpassa a formação que engloba saberes e reconhecimento de que a educação é intervenção no mundo. (FREIRE, 2019).

A formação do professor faz parte de um saber plural oriundo da formação profissional, de saberes disciplinares, curriculares e da experiência. Dessa forma, atentaremos para os saberes profissionais que são saberes oferecidos por instituições que formam os professores, e estão, na maioria das vezes no nível superior. (TARDIF, 2002).

Diante disso, apresentaremos, nas linhas que seguem elementos apreendidos em curso de Pós Graduação articulados com nossas práticas cotidianas no ofício de contadores de histórias.

\section{SOBRE AS TÉCNICAS DA PROFISSIONALIZAÇÃO DO CONTADOR DE HISTÓRIAS}

As técnicas são produções humanas que auxiliam o ser humano no exercício de diversas funções. Para isso procuramos entender como o contador ou mediador de histórias poderá e deverá escolher a melhor técnica ou forma de contar uma boa história.

A prática de contar histórias desenvolveu-se muito, do fim do século passado aos nossos dias. Hoje, como atividade artística, se beneficia de normas e técnicas. E, para não ficar reduzida à "hora do conto", em escolas e bibliotecas, exige do contador um aperfeiçoamento técnico, uma prática de leitor e 
um apuro crítico. E, para não haver confusão de linguagens, é preciso perceber que o contador de histórias contemporâneo difere de um contador popular, de um declamador e de um ator, ainda que sua prática se beneficie de elementos também utilizados por esses artistas". (SISTO, 2012, p. 33).

O projeto de Lei no 7.232, DE 2017 em seu artigo 3르, inciso V apresenta uma das competências do Contador de Histórias no que diz respeito a:

Fomentar a formação de pessoal qualificado para o exercício da profissão, por meio da pesquisa de repertório e o estudo de técnicas e dos respectivos recursos expressivos para contar e narrar.(p.2.)

A primeira peça fundamental de um contador ou mediador de história repousa no fato da compreensão de que todo ofício exige preparação, organização, planejamento, estudo, dedicação e treino, por isso, recorremos às técnicas individuais que são as específicas do contador ou mediador e as coletivas que se desenvolvem no espaço dialógico entre vários sujeitos.

Contar ou mediar histórias são ações diferentes que exigem interações distintas com o objeto de trabalho. Enquanto a ação de contar histórias trabalha com a enunciação oral (SISTO, 2012), a ação de mediar uma história o livro se apresenta como elemento de apoio e recurso enunciativo (BRENAMN, 2015). A mediação de histórias é uma prática muito utilizada nas salas de aula, de leitura e bibliotecas escolares.

A seguir, apresentaremos algumas técnicas apreendidas no exercício da ação educativa e nas formações e pesquisas acadêmicas.

\subsection{TÉCNICAS INDIVIDUAIS}

A premissa importante de um bom contador de histórias é o despertar do gosto e prazer em ler tudo que estiver ao alcance, é encontrar nas histórias o jeito lúdico de brincar com as palavras, coisas e vida. Diante disso, selecionamos cinco passos individuais que um contador ou mediador de histórias precisa desenvolver.

É preciso ter o gosto pela leitura, ler muito e constantemente, ter paixão pelo silêncio, escolha da história e conhecimento do público a que se destina, treino do texto, leitura e compreensão da história como produtora de significados os quais abordaremos nas linhas a seguir. 
1- Ler muito em intensa relação entre leitor e livro proporcionando novas possibilidades, sentidos e significações, pois ..."A grande dica para ser um narrador de contos é ler muito; os livros, as placas, os gestos, as pessoas, a vida que vai em cada coisa". (SISTO, 2012, p. 24). E assim ir exercitando o olhar sobre o contexto real de existência humana sempre em interação com os outros

2- O relacionamento com o silêncio é um elemento importante para a ação de contar ou mediar uma história. Significa organizar um tempo para desligar as falas exteriores e deixar que as vozes internas produzam sentido no texto.

E esse é o aprendizado mais difícil para o imediatismo que nos
assola[...]Só quando o silêncio interior se torna insuportável é
que o contador está pronto para contar uma história. É preciso
estar cheio de silêncio para que contar uma história seja
absolutamente necessário. Toda preparação de uma história
produz um rumor silencioso que vai se ampliando até explodir
na palavra num processo de maturação. (SISTO, 2012, p. 25).

Deixar de falar, por alguns instantes, é deixar fluir, permitir a materialização do que está nas entrelinhas das relações humanas. Significa garantir momentos de reflexões sobre o que será desenvolvido. Silenciar também é meditar consigo mesmo e com o outro num exercício de práxis. Abrir espaço entre o imaginário e o real, é humanizar-se dia a dia, costurando retalhos históricos culturais nos tempos e espaços não mensurados pelo homem. É buscar na memória ancestral de tradição oral a força de fazer escolhas em função do bem estar coletivo.

3- O terceiro item diz respeito a escolha da história que será trabalhada, fala de peculiaridades pessoais, de memórias, de afetos, de prazer e de seleção.

Para a escolha da história precisamos observar os nossos gostos pelo gênero literário, a qualidade literária da obra, o público alvo a que se destina a história, os objetivos a serem alcançados (cobrança de conteúdos que serão estudados, encantamento, prazer na leitura, formação do leitor).

Para Celso Sisto (2012) a escolha da história deve se adequar aos interesses do público, por isso a necessidade de um conhecimento prévio da comunidade a que a história se destina. Ela precisa ser bem construída, com características que identifiquem com um texto literário e que proporcione a partir de conflitos e soluções, maneiras diversas de questionamentos, reflexões ou debates, mesmo que interno e pessoal.

Para Abramovick (2009) quando se vai ler uma história, seja qual for, não se deve fazer isso de qualquer jeito. Não é bom pegar qualquer livro que 
estiver ao alcance, e, durante a leitura, demonstrar que não está familiarizado com o texto, com as palavras, pausando em lugares errados, fragmentando parágrafos por falta de fôlego, ou concluindo a história sendo que a ideia ainda permanece na página ao lado.

Diante disso, a escolha da história a ser contada deve preceder a leitura do livro para conhecimento do conteúdo da história, senti-la para que possamos emitir a emoção verdadeira, que vem lá de dentro, lá do fundinho, e que, consequentemente, chega ao ouvinte. (ABRAMIVICK, 2009)

4- $O$ quarto item para a organização de contações ou mediações de histórias diz respeito à memorização do texto sem repetições mecânicas, conhecendo melhor e interagindo mais com o texto, promovendo treinamento sempre. Ler e treinar são necessários para a contação. Importante destacar que textos muito extensos, com muitas rimas e aliterações, podem dificultar a contação, por isso a importância do planejamento sobre a escolha da históra que será contada ou mediada. Para não ficar muito cansativo, narrador poderá dividir o texto em etapas.

Claro que se pode contar qualquer história à criança: comprida, curta, de muito antigamente ou dos dias de hoje, contos de fadas, de fantasmas, realistas, lendas, histórias em forma de poesia ou de prosa... qualquer uma desde que ela seja bem conhecida do contador, escolhida porque a ache particularmente bela ou boa, porque tenha uma boa trama, porque seja divertida ou inesperada, ou porque dê margem para alguma discussão que pretende que aconteça, ou porque acalme uma aflição. O critério de seleção é do narrador. (ABRAMOVICK, 2009, [n.p]).

5-compreensão da história como produtora de significados.

Mas contar bem uma história é também saber evitar o didatismo e alição de moral; os estereótipos da palavra e dos gestos; o maniqueísmo e os preconceitos; o óbvio, o modismo e o lugar comum. (SISTO, 2012, p. 25).

Sendo assim, o contador precisa compreender que o mais importante na história não é o que acontece em si, mas a compreensão essencial, é o não dito, é o que acontece dentro de nós, durante a leitura e ou escuta de uma história. As histórias ao serem contadas, oferecem intenções que revelam afetos que podem elaborar experiências individuais auxiliando no processo de autoconhecimento. (BUSSATO, 2007, p. 75). 
Ler, reler, interagir, interpretar e significar o texto antes de contá-lo é também um dos fatores básicos de preparação individual de uma história, pois ao contarmos uma história precisamos ir além, desvendando nossas histórias internas e assim costurá-las às nossas construindo um emaranhado de ressignificações e mudanças.

6- O sexto item diz respeito ao ambiente e aos adereços e indumentárias para a narração. É preciso prestar atenção no espaço para a contação, luminosidade adequada, ventilação e local que permita a atividade sem interferência externa.

Se o ambiente de contação for numa biblioteca real ou virtual, o ideal é que tenha livros, almofadas, pufs, dedoches, fantoches, rádio, tv, DVD, computador, músicas e outros acessórios que favoreçam a imaginação.

Se o espaço for aberto de livre circulação, como copa de árvores, praças e jardins, é importante que o contador estabeleça critérios para contar para não comprometer o entendimento da história. O ideal é que se conte histórias mais curtas ou com agrupamentos menores de ouvintes.

\subsection{TÉCNICAS COLETIVAS}

Contar ou mediar é um exercício de interação com o outro por isso é uma prática coletiva que está para além da mera comunicação, é um instrumento de transformação do pensar, de inquietação e de reflexão. Por isso, é preciso seguir alguns passos os quais discutiremos a seguir:

1) Interação entre contador e ouvinte. Nesse espaço contador e ouvinte deverão estar envolvidos nas histórias criando e recriando situações a partir das pausas, dos silêncios, ações, gestos, e expressões de forma harmônica e colaborativa. (SISTO, 2012).

Os textos cumulativos são exemplos de ações em que os sujeitos vão dialogando durante o percurso da história. As repetições incentivam o público a compartilhar o conto. As histórias como Lolo Barnabé de Eva Furnari, Ah! Cambaxirra, se eu pudesse de Ana Maria Machado, A Casa Sonolente de Audrey Wood e Wood, são exemplos de histórias em que tanto contador ou mediador poderão interagir com o público no processo de contação.

2) Trabalho com resgates. Neste contexto vale entender que o trabalho com resgate diz respeito a valorização dos grupos prioritários e em situação de desvalorização. $O$ trabalho com Histórias indígenas, afro-brasileiras e negrobrasileiras são essenciais para o resgate de memórias.

Meu Avô Apolinário, de Daniel Munduruku, A Semente que veio da Árrica, livro de vários autores como Heloísa Pires Lima, George Gneka e Mário Lemos, são exemplos de histórias que contribuem para o resgate de memórias 
de grupos marginalizados, os quais despertam a reflexão sobre questões cotidianas. Em "A Moça Tecelã" de Marina Colassanti o papel da mulher que faz suas escolhas e depois desfaz destecendo o tear, merece destaque sobre o papel da mulher na busca pela valorização e reconhecimento social.

3) Recuperação de resgates da infância e imaginação. Com os contos de fadas, por exemplo, podemos resgatar as nossas infâncias. Construímos pontes o real encontradas nas histórias do Chapeuzinho vermelho, Bela Adormecida, que assim como ela, na versão de Charlles Perrault, todos habitantes do reino, exceto o Rei e a Rainha, dormiram durante um século, por uma maldição enunciada.

Diante disso, a partir das histórias podemos reencontrar com folguedos, medos e mitos, refazendo assim nossa trajetória afetiva, pessoal e coletiva. Redefinimos nossa imagem social e coletiva, a partir daquilo que nos tornamos, e consequentemente revisitamos nossa imagem social. Redimensionando nossas crenças mudamos e significamos nossa imaginação para a liberdade. Colocamo-nos no lugar de seres criadores e produtores de conhecimentos ao falarmos com o outro por meio da voz, conduzindo-o às histórias.

E é pelo desejo de falar com o outro que levantamos a voz. E
a matéria do nosso sonho- que a princípio pode parecer fugaz,
já que o ato de narrar oralmente não se perpetua no tempo e
no espaço-só encontrará eco se levar, num próximo passo, o
ouvinte ao livro. Aí sim, ao refazerem suas histórias de leitores,
o contador de histórias ocupará, nessas biografias, um lugar
especialmente resguardado pelo coração.(SISTO, p.27, 2012).

Nesse lugar resguardado pela sensibilidade dialogamos com os ouvintes a partir de atravessamentos que perpassam ouvir, ler e interagir para produção de sentidos e narrativas diversas.

\section{METODOLOGIA DA PESQUISA}

A pesquisa é bibliográfica em que selecionamos livros e artigos que tratam da Contação de Histórias e produção literária e os caminhos que dialogam com o Ensino de Ciências. Mergulhados no paradigma da crítica social, Freire (2019) afirma que a educação problematizadora confirma a dialogicidade e se faz dialógica ao romper com os esquemas da educação bancária e propor mudanças teórico-práticas.

A pesquisa é do tipo participante, em que a participação do pesquisador na formação coletiva de um grupo social assume relevância. O ponto de origem é social que parte da realidade dos sujeitos da pesquisa e busca a unidade 
entre teoria e prática refletidas criticamente, em que todo o processo de construção, desde a produção de dados, análise e resultados anseiam pela transformação (BRANDÃO, 2017).

Ainda de acordo com Brandão (2017), a pesquisa participante integra quatro propósitos que aborda a intencionalidade pedagógica com diálogos coletivos, vocação educativa e formadora. Aspira por processos participativos amplos e contínuos em construções coletivas de um saber partilhado em proximidade com os saberes populares. Apresenta reconhecimento vinculado aos saberes populares e permite abertura múltipla e fecunda a diversos campos de ação social.

Entendemos que a pesquisa participante intenciona na formação de pessoas, para que motivadas transformem as realidades e não somente resolvam problemas locais e ou restritos. Ainda que o propósito seja de um público específico a ação participativa da formação é o diferencial dessa pesquisa (BRANDÃO, 2017).

Mediante os fatos apresentados, as formações teórico-práticas em cursos de formação na Pós- Graduação e atuações na educação básicas, selecionamos três canais do You Tube para analisarmos e observarmos técnicas diferenciadas de contar histórias, bem como a profissionalização dos contadores que atuam em diferentes funções, além da docência.

\section{OBSERVAÇÃO EM CANAIS NO YOUTUBE: DIFERENTES FORMAS DE CONTAR HISTÓRIAS}

Selecionamos três canais de contadores de histórias para analisarmos os processos técnicos de organização e apresentação, bem como entendermos a proposta cosmopolita nos diversos espaços, formas e intencionalidades.

Para Brenamn (2012) a televisão e a Internet ocuparam o espaço físico do contador de histórias oral. No entanto, a oralidade é retomada nos compartilhamentos dos vídeos, porém de forma diferente. A rapidez da informação, o sentimento de ver os vídeos substitui o momento prazeroso e simbólico- imaginativo dos contos.

O primeiro canal escolhido foi do escritor e professor indígena Daniel Munduruku ${ }^{1}$ que escreve para jovens e crianças. $O$ autor afirma que a maneira de abordar a educação indígena se constituiu na reflexão sobre sua infância e adolescência na cultura dos povos originários (MUNDURUKU, 2009).

A escolha do canal se deu por conhecermos as obras literárias do Daniel que chegaram às bibliotecas públicas escolares por meio do PNLD (Programa

\footnotetext{
${ }_{1}^{1}$ Disponível em: www.danielmunduruku.blogspot.com.br
} 
Nacional do Livro Didático) e por compreendermos que em tempos modernos diversas formas de apresentação de histórias são elementos válidos para o ensino e aprendizagem. A contribuição do autor é de relevância. Vai de encontro ao cumprimento da Lei 11.645/08 em que a obrigatoriedade da temática indígena no currículo da Educação Básica deve ser garantida. (BRASIL, 2008)

O canal do Daniel foi criado em 2011 para compartilhar histórias e sabedorias dos povos indígenas brasileiros. Essas são passadas de pai para filhos e valorizam a cultura indígena. Daniel nasceu em Belém do Pará, na aldeia Munduruku. Já ganhou vários prêmios no Brasil e no exterior. Um dos seus livros mais importantes é o "Meu avô Apolinário um mergulho no rio da "minha" memória". Nesse livro, muitos contos são apresentados para o fortalecimento da identidade dos povos originários.

Ele está dividido em "DM TV, ECOHVALE, Jornada Literária do Vale Histórico e Daniel Munduruku indica. Na Playlist DM TV são apresentados 31 vídeos onde o autor participa de programas de TV e entrevistas com diversos grupos em que a temática literária indígena é abordada para a valorização étnica. Na playlist da Jornada Literária do Vale Histórico são disponibilizados 6 vídeos sobre o evento realizado no município de Lorena Estado de São Paulo, em que o debate é sobre a literatura para a Educação Básica, formação de professores e incentivo à criação de bibliotecas escolares. Na playlist do ECOHVALE (Encontro de Contadores de Histórias do Vale do Paraíba) são disponibilizados 2 vídeos sobre o movimento da leitura no evento e também a formação de professores. E na playlist Daniel indica apresenta-se uma coletânea de 5 vídeos onde o escritor apresenta dicas curtas para incentivo e leituras de seus livros.

Em observação do canal a temática científica é abordada de uma maneira interdisciplinar em que a conscientização ambiental e a valorização dos rios, florestas e a preservação da identidade indígena estão imbricadas na literatura de Munduruku, as quais merecem destaque.

O segundo canal escolhido foi da psicóloga e contadora de Histórias Ana Flávia Bassos ${ }^{2}$, criado no ano de 2013, em que se valoriza o poder das narrativas e a arte de Contas Histórias como um processo educativo pleno. Sisto (2012) diz que ao contar uma história abri-se um espaço para o pensamento mágico. A palavra evoca imagens, instaura a ordem mágicopoética, resultante do gesto sonoro e corporal, embalados em uma emissão emocional que leva o público a uma suspensão temporal (2012).

Por ser um canal que transmite afetividade e pela subjetividade na pesquisa, decidimos analisar o canal da Ana Flávia Bassos. O objetivo

${ }^{2}$ Disponível em: https://www.youtube.com/channel/UCuc5G5GgigEmSM2ug3g8kWQ 
apresentado é o de educar com histórias e o incentivo aos adultos que educam crianças.

A playlists está subdividida em: Sonorização das histórias com 4 vídeos Aprenda a Contar histórias para crianças com 14 vídeos, Histórias para crianças pequenas com 25 vídeos, Páscoa com 8 vídeos, Histórias com dobraduras com 9 vídeos, Atenção das crianças na hora de contar histórias com 6 vídeos, Férias escolares e histórias com 7 vídeos, Dicas de livrosHistórias de tirar o chapéu com 10 histórias, Dormir bem- para a hora de dormir com 6 vídeos, Alimentação e histórias com 9 vídeos, Criança e Naturezacriança saudável 6 vídeos, Brinquedos que vem da natureza 8 vídeos, GestosPor que, quando e como contar histórias com gestos 5 vídeos, Natal- Histórias, atividades e inspirações 16 vídeos, Danças infantis para usar com histórias são 7 vídeos, Dicas práticas para o dia a dia com crianças com 9 vídeos.

A diversidade nas temáticas das Playlists "Brinquedos que vêm da natureza", "Criança e Natureza = a criança saudável" e "Alimentação e Histórias" são abordagens que incentivam a Educação em Ciências, a imaginação, a leitura deleite e a afetividade. A escolha por apresentar, em sua grande maioria, vídeos curtos facilitam o ensino e a dinâmica da sociedade atual.

O terceiro canal escolhido foi "Fafá conta histórias"3, da atriz Flávia Scherner criado em 2015, em que a Youtuber conta histórias para todas as pessoas. A Playlist está subdivida em temas como: Histórias de Princesas e Princípes com 11 vídeos, Histórias de empoderamento com 23 vídeos, Histórias clássicas com 21 histórias, Dias das Mães com 19 histórias, Desenhos com histórias com 1 vídeo, Histórias de adoção com 3 vídeos, Educação Sexual na quarentena com 3 vídeos, A revolução das princesas com 3 vídeos.

Observamos que a atriz conta histórias utilizando vários elementos de arte, encenação, utilização de elementos didáticos como livos, fantoches, brinquedos e etc. Percebemos que alguns vídeos tem a participação do profissional e intérprete de libras, uma proposta inclusiva para valorização do surdo, quesito fundamental para a igualdade de oportunidades em uma sociedade tão desigual.

Levantamos esses dados para conhecer o que já foi construído em alguns canais do Youtube sobre a Contação de Histórias, bem como os diálogos transversais e interdisciplinares para o Ensino de Ciências para as docências. Percebemos que os três canais foram fundamentais para analisarmos o papel da literatura apresentada, a profissionalização do contador de histórias, a subjetividade na escolha das temáticas e o incentivo à leitura,

${ }^{3}$ https://www.youtube.com/channel/UC9fxSdFicz5QWDEhYCk k1w 
imaginação, educar com histórias, inclusão indígena, social e Ensino de Ciências.

O estudo sobre esses canais foram importantes para percebemos como as contações de histórias podem ser desenvolvidas em vários espaços, com técnicas diferentes, com profissionais de diferentes áreas como docentes, atores, escritores, ilustradores, psicólogos entre outros.

\section{CONSIDERAÇÕES FINAIS}

A formação para atuação como contador de histórias no espaço escolar perpassa pela profissionalização que pode acontecer, atualmente, na PósGraduação. É nesse espaço dinâmico que se dá a tríade relação entre ensino, pesquisa e extensão.

Ensino diz respeito ao ato interativo de compartilhar saberes, logo não é transferência de conhecimento, mas algo que precisa ser testemunhado e vivido. O professor deve levar em conta sua competência profissional, deve estudar, se esforçar para que sua ação tenha qualidade. (FREIRE, 2019). A pesquisa é parte do trabalho docente, não há ensino sem pesquisa, dessa forma o compromisso do educador é com a formação da consciência crítica do educando. (FREIRE, 2019). E a extensão é um dos caminhos possíveis de comunicação entre a sociedade e a Universidade por meio de cursos de curta duração que auxiliarão as demandas profissionais ao suscitar a relação entre teoria e prática.

O contador de histórias da antiguidade enunciava em um território de comunicação restrita a sua comunidade local. Os saberes eram compartilhados pela linguagem oral dos narradores tradicionais e muitos conhecimentos chegaram até nós por meio dos mitos, fábulas, contos de fadas e muitas histórias de uma forma geral.

Com as novas demandas é preciso investir na profissionalização do Contador de Histórias para ações mais amplas e globais. Os espaços e formas de atuação educativa propõem a pesquisa, o ensino e a extensão como parte desse processo de formação em diálogo entre Pós-Graduação e a sala de aula.

Investir na formação do professor para a utilização da arte de Contar Histórias é um percurso que exige profissionalização para ações de transformação social. Significa sair do lugar comum e adentrar na pesquisa em que trabalho e profissionalização sejam capazes de humanizar e não escravizar pelo trabalho.

Que a pesquisa na Pós Graduação alcance, de fato, as demandas sociais formando profissionais Contadores de Histórias capazes de participarem a serviço da sociedade. 


\section{REFERÊNCIAS}

Brasil. Lei de no 11.645 de 10 de março de 2008. Disponível em: http://www.planalto.gov.br/ccivil 03/ Ato2007-2010/2008/Lei/L11645.htm Acesso em: 19 de junho de 2020.

BRENMAMN, Ilan. Através da vidraça da escola: formando novos leitores/ Ilan Brenamn 2.ed.-Belo Horizonte:Aletria, 2012.

CENDALES, Lola. TORRES, Fernando. TORRES, Alfonso. A semente tem sua própria dinâmica: sobre as origens e os rumos da investigaciónaccion participante (IAP): Entrevista com Orlando Fals Borda- In: A pesquisa participante: A partilha do saber/Carlos Rodrigues Brandão, Danilo R, Streck (organizadores). Aparecida-SP: Ideias \& Letras, 2017.

FREIRE. Paulo. 1921-1997.Pedagogia da autonomia saberes necessários à prática educativa /Paulo Freire. 62 ${ }^{\mathrm{a}}$ ed-Rio de Janeiro/São Paulo, Paz e Terra, 2019.

FREIRE. Paulo.1921-1997. Pedagogia do Oprimido/ Paulo Freire. -73.ed.Rio de Janeiro/São Paulo: Paz e Terra, 2020.

TARDIF, Maurice. Saberes docentes e formação profissional. $4^{\mathrm{a}}$ Ed. Rio de Janeiro: Vozes, 2002.

MUNDURUKU. Daniel. Educação indígena: do corpo, da mente e do espírito. Revista Múltiplas Leituras, v.2, n. 1, p. 21-29, jan. / jun. 2009. Disponível em: https://www.metodista.br/revistas/revistasims/index.php/ML/index . Acesso em: 19 de junho de 2020.

VANSINA, Jan. (2010). A tradição oral e sua metodologia. In: KIZERBO, J. Coordenador. História Geral da África: I metodologia e Pré História da África. São Paulo: Ática; UNESCO, 2010. 992p. Disponível em: http://unesdoc.unesco.org/images/0019/001902/190249por.pdfAcesso em: jan. 2019.

PROJETO DE LEI N.․ 7.232, DE 2017 (Da Sra. Erika Kokay). Disponíel: camara.leg.br/proposicoesWeb/prop_mostrarintegra;jsessionid=32A8514A49 BBBC8C690898CC1FD70954. proposicoesWebExterno2? codteor $=1543773 \& f$ ilename=Avulso+-PL+7232/2017 Acesso em: 25/09/20 20.

BUSATTO, Cléo. A arte de contar histórias no século XXI: tradição e ciberespaço. Petrópolis, RJ: Vozes, 2006.

CARVALHO.Márcia Evelin de. Form@re. Revista do Plano Nacional de Formação de Professores da Educação Básica./ Universidade Federal do Piauí, Teresina, v. 3, n. 2, p. 19-32, jul. / dez. 2015. 
SISTO, Celso. Textos \& pretextos sobre a arte de contar histórias.

3d.rev.ampl.-Belo Horizonte: Aletria, 2012. 